\title{
Evaluation of the influence of geographical factors on the difficulty of grid operation cost
}

\author{
Geli Zhang ${ }^{1 *}$, Heng Zhang ${ }^{l}$, Yan Zheng ${ }^{l}$,Yaqiong Liu ${ }^{l}$,Tong $\mathrm{Li}^{1}$,Meibao Wang and Xiaohui Wang ${ }^{1}$ \\ ${ }^{1}$ State Grid Economic and Technological Research Institute Co. Ltd., Beijing, China
}

\begin{abstract}
The cost of power network operation and maintenance is affected by many factors, which will affect the cost. Among the many influencing factors, the geographical environment is one of the more important factors. The influence of geographical factors on cost is realized by geographical conditions including distance, topography, climate, etc. . When the distance is longer, the topography is more complex, and the climate change is more severe, for the operation and maintenance costs will have a higher increase in the effect.This paper analyzes the process that the internal and external composing mechanism of Power Grid Enterprise's operation cost is affected by geographical factors, and analyzes the influence way and result of geographical factors on power grid's operation cost.
\end{abstract}

\section{Introduction}

The study of power grid cost is always an important research hotspot. For the enterprise management, the cost determines the final business results of the important output indicators: The level of profits. When the profits of enterprises are high, more resources will be put into reproduction, and the enterprises will be more capable of stepping onto the track of sustainable development.

Guided by China's domestic power reform policies, the power industry sector, especially grid enterprises, needs to deal with the regulatory authorities: The Energy Bureau's Electricity Price Regulation, in order to limit the monopoly profit of power grid, which is a natural monopoly, the supervision of transmission and distribution cost is an important part of the price supervision. To some extent, the price of electricity directly depends on the transmission and distribution cost of power grid enterprises, especially the cost of operation and maintenance.

But at present, the closed-loop Cost Management of power grid enterprises has not formed a perfect management system, and the current management level still can not meet the high requirements of accurate management and control costs. In order to push the management level of power grid enterprises to a higher level and increase the grasp of cost management, it is of great significance to carry out the research on transmission and distribution cost of power grid enterprises.

Among them, operation and maintenance cost is the main cost of power grid operation, its cost management was extensive in the past, in 27 provincial companies management differences, did not form a unified and efficient company-level management system. In order to achieve the objectives of management system such as life- cycle management, cost budget management, cost externalization and multi-dimensional lean management, it is necessary to link the labor, material, outsourcing, mechanical cost of operation and maintenance equipment with operation and maintenance activities, to realize the quantitative control of operation and maintenance cost by operation and maintenance standardization cost.

In order to study the cost of power grid, we first need to determine the factors that affect the cost. For the operation and maintenance of substations and lines located in the mountains, hills and plains outside the city, geographical factors will be a major factor affecting the cost of operation and maintenance, so it should be explored from the inside and outside of the impact of geographical factors on the type of power grid cost.

In the related research field of power system, the research of comprehensive evaluation method focuses on the combination of subjective and objective weight and the comprehensive utilization of several methods. The objectivity of the evaluation method is often considered in the traditional evaluation, and the combination weight method is used to make the weight calculation process objective, delphi, AHP, FAHP, principal component method, entropy weight method, grey correlation method, sequence synthesis-g1 method, matter-element extension method and other methods are used to improve the objectivity of weight, but the consistency of different methods is ignored.

* Corresponding author: fredistheone@ $126 . c 0 m$ 


\section{Geographical factors assessment of grid operation cost}

\subsection{Evaluation Index}

In order to analyze the internal and external influence factors, we should first establish the influence factors index and construct the index system. The source of influencing factor index is the expert experience of Transportation and inspection management. By summarizing the key index in the past, the key index under the geographical influence of cost is formed and the index system is constituted.

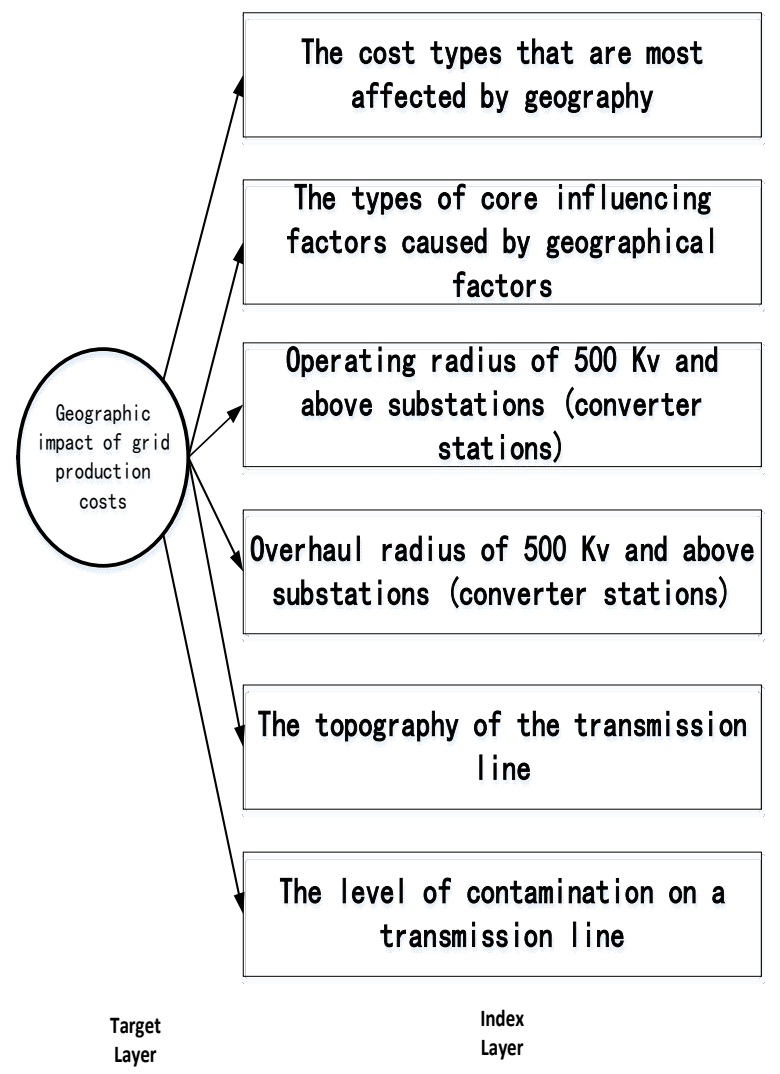

Fig. 1. Hierarchy of indicator system

(1) Among the cost types which are most affected by geographical factors: The value types include labor cost, material cost, travel cost, outsourcing cost[1-10], storage cost, and other costs.

(2) The value of the core factors caused by geographical factors: The value of the type of operation and maintenance radius, climate factors, channel environment, terrain factor, pollution level, three-span quantity, other factors.

(3) The radius of operation and maintenance of $500 \mathrm{kV}$ and above substations (converter stations), the range of which is less than $50 \mathrm{~km}, 50-100 \mathrm{~km}, 100-200 \mathrm{~km}$ and more than $200 \mathrm{~km}$. The design corresponding 4 grade values are 1 under $50 \mathrm{~km}, 2$ under $50-100 \mathrm{~km}, 3$ under $100-200 \mathrm{~km}$ and 4 over $200 \mathrm{~km}$.

(4)The maintenance radius of $500 \mathrm{kV}$ and above substations (converter stations) is less than $50 \mathrm{~km}, 50$ $100 \mathrm{~km}, 100-200 \mathrm{~km}$ and more than $200 \mathrm{~km}$. The design corresponding 4 grade values are 1 under $50 \mathrm{~km}, 2$ under $50-100 \mathrm{~km}, 3$ under $100-200 \mathrm{~km}$ and 4 over $200 \mathrm{~km}$.

(5)The terrain in which the transmission line is located shall be defined as plains, hills, mountainous areas, and others. According to the measurement index of operation, maintenance and repair difficulty, the design corresponds to 4 levels of values, 1 for the plain, 2 for the hills, 3 for the mountains, and 4 for the others.

(6)The pollution level of the transmission line is below grade $\mathrm{C}$, above grade $\mathrm{C}$ and above Grade $\mathrm{D}$. The corresponding value of grade 3 is 1 below grade C, 2 above grade $\mathrm{C}$ and 3 above Grade $\mathrm{D}$. The title is set in bold 16-point Arial, justified. The first letter of the title should be capitalised with the rest in lower case. You should leave $35 \mathrm{~mm}$ of space above the title and $6 \mathrm{~mm}$ after the title.

\subsection{Evaluation Index System}

When using AHP to do the system analysis, we need to divide the index system into several levels and form the index system of several levels. Hierarchical structure is divided into objectives, elements and indicators of the three layers. The target layer[11-13] is a comprehensive index formed by the Final Assembly, and it is the basis of ranking. The indicator layer represents the various measures, policies and programs to be chosen to solve the problem.

According to the evaluation content, this paper puts forward the two-layer structure of the evaluation system of operation and maintenance cost geographic impact as follows: Index name, index type, index direction, cost type whose value interval is most affected by geographical factors, the radius of operation and maintenance of $500 \mathrm{kv}$ and above substations (converter stations), the interval index, the greater the impact on the results, the greater the maintenance radius, the interval index of $500 \mathrm{kv}$ and above substations (converter stations), the greater the impact on the result, the greater the impact on the result, the greater the impact on the result, the greater the impact on the terrain, the pollution level and interval index of the transmission line.

The calculation method of the index is formed by the historical cost data, so the index data has practical significance and can guide the future cost management through the cost data that happened in the past. Taking the operation and maintenance cost of $500 \mathrm{kv}$ substation as an example, this paper illustrates that the cost is affected by geographical factors.

\subsection{Comprehensive evaluation method}

After the formation of the index system, it is necessary to combine the comprehensive evaluation method to form the final analysis results.In order to determine the degree of analyzing the geographical influence cost, it is necessary to use the index Quantitative analysis to determine the influence of the overall geographical factors on the cost management, and to adopt the comprehensive evaluation method to form the quantitative conclusion of the comprehensive evaluation. 
The method of comprehensive evaluation can choose analytic hierarchy process or other evaluation methods. Through the index value of the set index system, the weight is given to realize the aggregation of evaluation conclusions. The weight can be calculated synthetically by the entropy weight method.

In the analysis example of this paper, the cost of materials, labor, outsourcing costs can be considered as the basic cost of the cost composition, referred to as the three maintenance costs, through the above three costs as the basis, can form the basic framework of cost analysis, combined with the geographical attributes of the cost, we can analyze the changes of the above three kinds of expenses under the factors of terrain, climate, distance, etc.

\section{Analysis on the influence of geographical factors on the three-fee of maintenance}

\subsection{Content of the three-fee of maintenance}

According to the foregoing, the three maintenance fees include material costs, labor costs, outsourcing costs. These three types of costs are respectively the labor costs resulting from the wages of the maintenance personnel and the wages of other personnel involved in the maintenance activities. These types of costs are related to the types of maintenance operations that occur, and the more complex the maintenance operations, the more labor costs, generally speaking, labor costs should be standardized quota data, easier to control, but also by the national wage standards with changes in economic development, generally shows an upward trend. With the increase of manpower, the maintenance cost, that is, the maintenance cost will also rise, which brings pressure to control the maintenance cost.

Material cost is the cost of purchasing materials used in maintenance, which is usually related to the price and quantity of materials used in maintenance. When the maintenance work is more mature, the use of materials is smaller, so the cost of materials is smaller, when the price of materials is lower, the cost of materials is smaller. Therefore, in the management of material costs, the first priority should be to detect changes in material prices in a timely manner, to increase the volume of purchases as prices fall, to decrease as prices rise, and to predict future changes in material prices and propose solutions. Constantly promote the progress of maintenance technology, with more cost-effective materials to complete higher-quality maintenance, innovation, maintenance business to achieve high-quality development.

The three maintenance fees are the comprehensive result of the deep development of the financial dimension of the cost management of power grid enterprises, that is to say, to control the maintenance cost of power grid is to control the three maintenance fees, from the expenses of Labor, materials and outsourcing, lean control of the cost of maintenance expenditure. In the digital background, to determine the core of the maintenance cost types, the cost of a good path to enhance the purpose of data collection, and the follow-up use of data assets analysis of cost and expenditure characteristics and weak links have greater significance.

\subsection{Major geographical factors}

The power transmission and transformation facilities of the company cover a wide area and vary greatly. Through investigation and research, the first is to understand the influence factors and priority of transmission line and Substation Geographic Environment on operation, maintenance and repair cost; the second is to understand the topographic distribution and pollution grade distribution of transmission lines $35 \mathrm{kv}$ and above, the distribution of operation and maintenance radius and maintenance radius of $500 \mathrm{kv}$ and above substations can provide a basis for setting the Adjustment Coefficient of transmission and substation operation and maintenance cost budget.

It is found that geographical environment mainly affects labor cost, travel cost and outsourcing cost. According to the factors, it is found that the main factors affecting the cost of power transmission inspection are the radius of operation and maintenance, channel environment and terrain. The operation and maintenance radius, maintenance radius and pollution level are the main factors that affect the cost of substation operation and inspection. Specifically, $84 \%$ of the company's $500 \mathrm{Kv}$ and above substations have an operating radius of less than $100 \mathrm{~km}$, while the maintenance radius is evenly distributed between 1-200 km companies.

The company's $35 \mathrm{kv}$ and above transmission lines are located mainly in the plain and hilly Hoe San Estate, with the length of transmission lines accounting for $93 \%$. According to the pollution level, the pollution level of transmission lines is mainly distributed below grade $\mathrm{C}$, Grade C and Grade D, 89\% of the line length.

\section{Operation maintenance management system}

This part of research aims to understand the provincial power grid assets and cross-regional power grid assets operation and maintenance management system. Survey found that the provincial power grid assets operation and maintenance management of provincial inspection and maintenance companies, transmission and distribution companies and power supply companies. The operating voltage range of maintenance assets varies among maintenance companies. Generally speaking, provincial maintenance companies mainly operate and maintain power facilities of $500 \mathrm{KV}$ and above, among them, the maintenance companies of Beijing, Shanghai, Chongqing and Heilongjiang Operate and maintain $500 \mathrm{kv}$ and above and some $220 \mathrm{kv}$ power facilities, and the maintenance companies of Tianjin operate and maintain $220 \mathrm{kv}$ and above power facilities, operation and maintenance of 330 $\mathrm{kv}$ and above power facilities in Qinghai maintenance company. 
In addition, at the level of prefectural and municipal companies, there are cases of co-working or complete separation between the transportation and Inspection Department (Equipment Department) and the inspection and repair branch, of which 9 are co-working units, accounting for $33.33 \%$, and 13 are completely separated, accounting for $48.15 \%$. As the transmission and Distribution Company is a subsidiary of the provincial company, the operation and maintenance of the assets of the provincial company and maintenance of assets is mainly based on the provincial inspection and repair companies signed contracts.

As for the operation and maintenance of trans-regional assets, the main operation and maintenance organizations of trans-regional assets are provincial inspection and maintenance companies and transmission and distribution companies, and the main operation and maintenance organizations of trans-regional assets are provincial inspection and maintenance companies, and maintenance cost management is mainly incorporated into the provincial company after the unified budget management. The provincial power grid assets operation and maintenance units are mainly provincial maintenance companies, power transmission and transformation companies and local power supply companies. The situation involves 15 units (accounting for $55.56 \%$ ), the operation and maintenance organizations of 5 provincial grid assets are provincial inspection and Maintenance Company (DC transportation and Inspection Company) and local power supply company, accounting for $18.52 \%$. In addition, the assets of Shanxi Province also includes the provincial transmission maintenance company, management and other units are different.

The transportation and Inspection Department (Equipment Department) of the prefectural and municipal company is completely separated from the inspection and repair branch and coexists with the joint office. Among them, 13 units transportation and Inspection Department and Inspection and repair branch completely separate management, accounting for $48.15 \%, 9$ companies transportation and Inspection Department and Inspection and repair branch co-office, accounting for $33.33 \%$. In addition, Hebei and Sichuan companies have some professional co-working situations, the co-working ratio is $204 \%$ and $43.48 \%$ respectively.

Provincial Maintenance Company (DC transportation and Inspection Company) mainly operate and maintain $500 \mathrm{kv}$ and above power facilities, some units exist maintenance company operation and maintenance $220 \mathrm{kv}$ and above provincial assets. The maintenance companies of 18 units operated and maintained $500 \mathrm{KV}$ and some $220 \mathrm{kv}$ power facilities, accounting for $66.67 \%$; the maintenance companies of 4 units in Beijing, Shanghai, Chongqing and Heilongjiang operated and maintained $500 \mathrm{kv}$ and above and some $220 \mathrm{kv}$ power facilities, accounting for $14.81 \%$; Tianjin Maintenance Company operation and maintenance of $220 \mathrm{kv}$ and above power facilities; Qinghai Maintenance Company mainly operation and maintenance of $330 \mathrm{kv}$ and above power facilities.

As the transmission and distribution companies are subsidiaries of provincial companies, there are problems of compliance and legality of the assets of the operation and maintenance companies, the basis for the operation and maintenance of the assets of the provincial company and the assets of the maintenance agent of the power transmission and distribution company is mainly through the signing of contracts between the power transmission and distribution company and the provincial maintenance and repair company, involving 18 units, accounting for $66.67 \%$ of the total, of which 12 units sign contracts through decision-making procedures, six units based on the framework form of bidding. In addition, Shanxi Company set up a separate power transmission and maintenance company, operation and maintenance of 500 $\mathrm{kv}$ and above transmission lines and their power facilities, Shanghai, Shandong and Zhejiang Company transmission and Distribution Company is not operating and maintenance province assets, Beijing company no transmission and Distribution Company.

\section{Conclusion}

First, the preparation of production cost project management standards. According to the activity types of production cost, different project types, different project management processes, responsibilities of each management link, process control depth and settlement filing requirements are defined.

Second, to promote the entire process of production cost information management. Based on PMS, ERP, or selfbuilt system, it realizes the information management of requirement, plan, implementation process, settlement and filing of cost project.

Third, carding and improving the standard item library. According to the nature of different projects, the requirements of project management, and other factors such as the special focus of each specialty, the standard project database of production cost is revised on a rolling basis, through the standard project library clear project specification naming, research preparation and evaluation, project process control and data archiving project management norms.

Fourth, further standardize the production cost project WBS structure. materials, services and other, respectively used under the project material detail, service list, and can research, design, supervision, review cost classification management.

On the basis of the application of the research results in Article 11, combined with the actual management situation, equipment status, geographical environment and other factors of each unit's operation and maintenance business, work closely with the finance department to carry out the standard cost localization transformation. Based on the "operation cost standard of power grid production and operation" mentioned in Article no. 11 of State Grid Finance [2020] , and in the light of the actual situation of this province, the localization transformation is carried out, including local operation addition and calculation of Adjustment Coefficient, power grid production and operation activity-based cost standards" related content can consult the Ministry of Finance.

One is to carry out the localization transformation of the Standard Operation Library. For the types of equipment and activities not covered in the standard for operating 
costs of power grid production and operation, the additional fields are basically consistent with the fields covered in the standard for operating costs of power grid production and operation, including operation name, voltage grade, capacity, equipment unit, personnel name, unit, unit price, quantity, amount. The other is to calculate the regional adjustment coefficient. According to the actual situation of operation, maintenance and repair work in this province, the adjustment Coefficient of the equipment layer of this unit is calculated, taking into account the factors such as operation frequency, unit price of materials, geographical environment, etc., it makes the product of the original equipment cost and the adjustment Coefficient in the standard of power grid production and operation cost accord with the situation of this province basically. The municipal units of each locality may measure and determine the adjustment Coefficient of each locality according to the actual situation.

\section{Acknowledgments}

The fund support comes from: The research of reasonable configuration of operation and maintenance cost difference based on equipment status (ZZKJ-2021-10)

\section{References}

1. Katzenstein W, Apt J. The cost of wind power variability[J]. Energy Policy, 2012, 51(DEC.):233243.

2. Murr W C. Remote power cost display system: US, US5635895 A[P]. 1997.

3. Lamedica R, Esposito G, Tironi E, et al. A survey on power quality cost in industrial customers[C]// Power Engineering Society Winter Meeting. IEEE, 2001.

4. Morris R P. Methods, Systems, And Computer Program Products For Controlling Data Transmission Based On Power Cost[J]. US, 2007.

5. Chung C Y, Chung T S, Lin C W Y X J. Cost-based reactive power pricing with voltage security consideration in restructured power systems[J]. Electric Power Systems Research, 2004, 70(2):85-91.

6. Cole F A, Deben W A, Swartz R C. Power-cost efficiency of eight macrobenthic sampling schemes in Puget Sound[J]. Canadian Journal of Fisheries and Aquatic Sciences, 1989, 46(12):2157-2165.

7. Batista J, Alfonso J L, Martins J S. Low-cost power quality monitor based on a $\mathrm{PC}[\mathrm{C}] / /$ IEEE International Symposium on Industrial Electronics. IEEE, 2003.

8. Chen S L, Wang J G. VLSI implementation of lowpower cost-efficient lossless ECG encoder design for wireless healthcare monitoring application[J]. Electronics Letters, 2013, 49(2):91-92.

9. Sanyal S K. Cost of Geothermal Power and Factors that Affect it $[\mathrm{J}]$. proceedings world geothermal congress, 2005.

10. Yan D, Yixin N, Fushuan W, et al. REACTIVE POWER PRICING BASED ON COST
ALLOCATION THROUGH POWER FLOW TRACING[J]. AUTOMATION OF ELECTRIC POWER SYSTEMS, 2000.

11. Weng Z, Shi L, Xu Z, et al. Power system dynamic economic dispatch incorporating wind power cost[J]. Proceedings of the Csee, 2014, 34(4):514-523.

12. Achayuthakan C, Ongsakul W. TVAC-PSO based optimal reactive power dispatch for reactive power cost allocation under deregulated environment[J]. IEEE, 2009.

13. Chang H C, Chang H K, Jin S K. Power Cost Analysis of Go-ri Nuclear Power Plant Units 1 and 2[J]. Physics Letters B, 1976, 215(4):617-623.

14. Hicks M, Egan C, Christianson B, et al. Reducing the Branch Power Cost in Embedded Processors Through Static Scheduling, Profiling and SuperBlock Formation[C]// Advances in Computer Systems Architecture, 11th Asia-Pacific Conference, ACSAC 2006, Shanghai, China, September 6-8, 2006, Proceedings. Springer-Verlag, 2006.

15. Schwieger, Bob. Northside's CFB repowering halves power cost, reduces emissions. [J]. Power, 2002. 